\title{
Design ANd Optimization Of PUMPINg Aggregate For Hydraulic Active Car SuSPENSION USING SOFTWARE SOLIDWORKS
}

\author{
Kemajl Stuja, Günther Poszvek, Erich Markl, Mohamed Aburaia
}

Höchstädtplatz 6, 1200 Wien, Austria

\begin{abstract}
This work represents the design and performance optimization of pumping aggregate for hydraulic active car suspension systems. For solving of this task is required wide scope of interdisciplinary knowledge. The software used in this project was SolidWorks from Dassault Systemes. Using this tool is possible to analyse and optimize the flow of hydraulic fluid throw the electromotor of pumping aggregate. This papers shows among other, how to set the input parameters and constraints such as pressure and velocity, how to simulate a rotating flow of cooling fluid inside intermediate regions between stator and rotor. For approving a required lifetime of pumping aggregate a fatigue analysis was done and represented above. The verification of simulation model and mandatory validation of simulation results are made. The conclusions at the end of this work have confirmed the usage of computational fluid dynamic - software for future researches of pumping aggregates.
\end{abstract}

Keywords: Design; Modelling; Simulation; Optimization; Pumping Aggregate
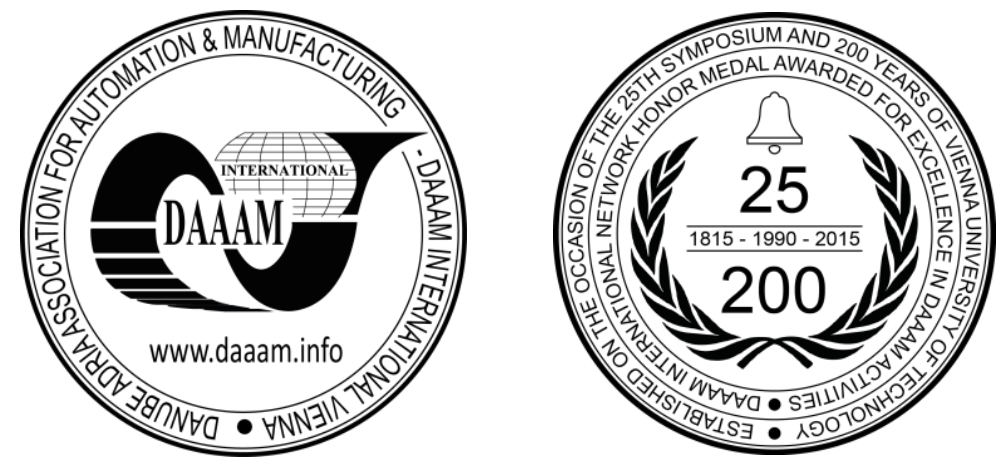

This Publication has to be referred as: Stuja, K[emajl]; Poszvek, G[unther]; Markl, E[rich] \& Aburaia, M[ohamed] (2016). Design and Optimization of Pumping Aggregate for Hydraulic Active Car Suspension using Software SolidWorks, Proceedings of the 26th DAAAM International Symposium, pp.0142-0146, B. Katalinic (Ed.), Published by DAAAM International, ISBN 978-3-902734-07-5, ISSN 1726-9679, Vienna, Austria DOI:10.2507/26th.daaam.proceedings.020 


\section{Introduction}

The objective of industrial engineering is to design, to improve and to optimize technical products almost keeping the cost down. The most advanced part of this practise is the computer aided engineering (CAE), which take care about design, simulation and optimization of virtual products. A car suspension system consists of spring and shock absorber that connect the wheel to the chassis that allow them to control wheel movement and to provide good road-holding conditions. An active suspension system uses software, computers, sensors and actuators to dynamically control what each wheel does. That means, this technology aids a soft springs - keeping all tires in optimum contact with the road surface while "isolating" the chassis and passengers from shocks. This technology according to [1] came in the 1980 and firstly was used in Formula 1. Early active systems used in Formula1 used hydraulic actuators to keep the car as flat and level to the ground as possible, also allowing an optimal grip to all wheels. Firstly was this technology too complex and too expensive for wide use. Currently electronics are very small and are very inexpensive. Computers are taking over modern cars, allowing it to assist in each situation on the traffic. Furthermore the computer will be the central part of the modern car in the future enabling the engineer to integrate systems for active suspension control. The aim of this work is to show the practise of this tool for design and improve of performance of pumping aggregate for hydraulic active car suspension. The heart of this system is the electromotor, which task is to drive the pumping gears, in order to react quickly to active car suspensions. For solving of this task is required wide scope of interdisciplinary knowledge like a continuum mechanics, hydraulics, thermodynamics, manufacturing etc. The conventional analytic methods and tools for solving of this kind of tasks are very complex and time consuming. Therefore shows this work another productive approach for solving a complex engineering tasks in relative short time, almost keeping the cost down. Hereafter shows this work the practice of 3D modelling software SolidWorks of Dassault Systemes.

\section{Problem Statement}

The active suspension systems consist of: mechatronic shock absorber for each wheel, pumping aggregate and hydraulic pipes. The heart of these systems is the pumping aggregate which allows pushing the fluid very fast to the affected wheel. In the Figure 1a was shown the simplified sketch of this subsystem. Further the pumping aggregate consists of: electromotor, gearwheels and Electronic-box.

The design of the electromotor was the objective of this project. The main parts of the electromotor are:

- housing,

- rotor,

- $\quad$ rotor shaft (sliding contact bearing)

- Stator and wire windings.

As we can see in the Figure $1 \mathrm{~b}$ the fluid flows through the Inlet, inside to the electromotor keeping they cool. The most affected parts of the electromotor are the stator and rotor. The fluid flows within intermediate regions between stator and rotor and leaves the electromotor to the outlet.

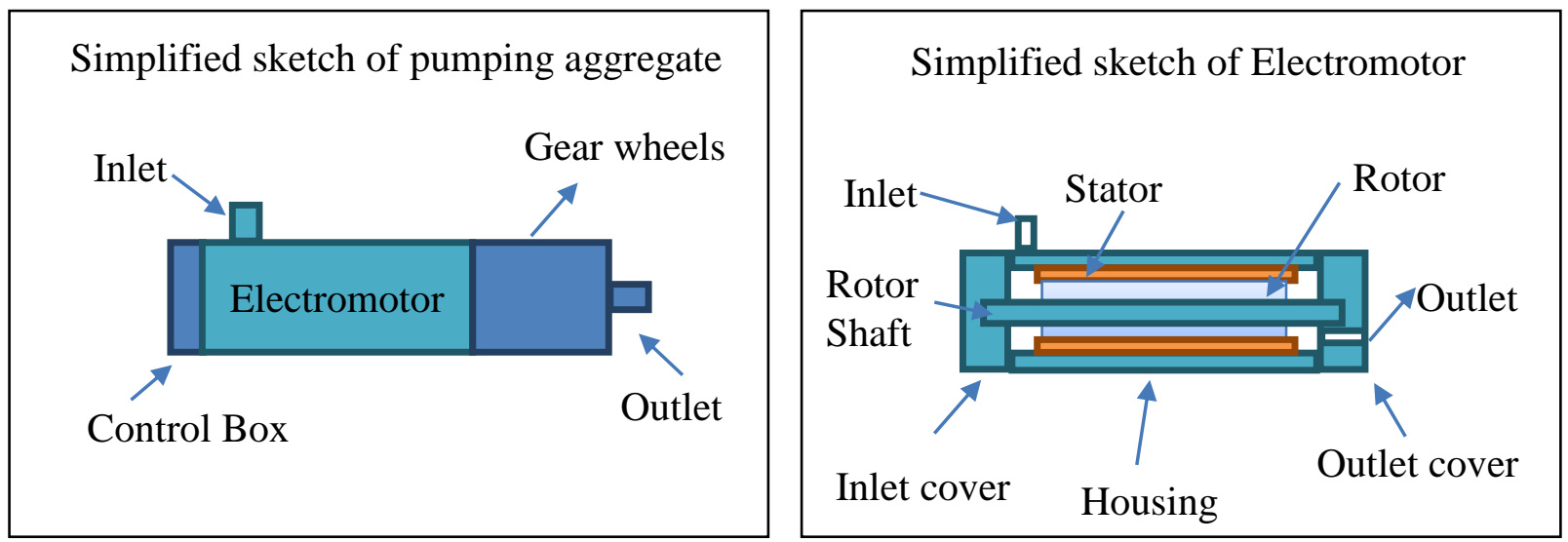

Fig. 1. (a) Pumping aggregate; (b) electromotor 


\section{Design and optimization of electrical motor for pumping aggregate}

\subsection{Requirements and constraints}

The first step of this project was the mechanical design of electromotor. The software tool used for 3D modelling was SolidWorks from Dassault Systemes. The SolidWorks software is very productive tool, capable to design, simulate and optimize solid parts with a giant bibliotheca of materials. The most advantages of this tool are working in same environment. That means a converting of data from one software system to other isn't required. Intuitive user interface of SolidWorks enable engineer to quickly transform ideas into great products.

Requirements and Constraints for electromotor

\begin{tabular}{lll}
\hline Requirements and Constraints & Minimal [unit] & Maximal [unit] \\
\hline Length & $80 \mathrm{~mm}$ & $160 \mathrm{~mm}$ \\
Diameter & $60 \mathrm{~mm}$ & $120 \mathrm{~mm}$ \\
Rotation Rotor & 0 & $4500 \mathrm{rpm}$ \\
Flow rate & 0 & 71 \\
Pressure Inlet & $2 \mathrm{Bar}$ & $50 \mathrm{Bar}$ \\
Pressure Outlet & $2 \mathrm{Bar}$ & $50 \mathrm{Bar}$ \\
Material & corrosion resistant & \\
Fluid & Pentosin & \\
Lifetime & 500000 Cycles & \\
\hline
\end{tabular}

Table 1. An example of a table

\subsection{Design and mechanical optimization}

The mechanical design of electromotor is comprehensive task. For a correct design, the limitation and constraints of the table 1 must be used into account. As showed in table1, the parts of electromotor must to sustain the variable fluid pressure in range from 2- 50 Bar. The aluminium alloy 2024 used for housing and the two covers. Aluminium cast was used for stator as well as for rotor and cooper for wiring. Every single part is optimized for this range of pressure. The Figure 2 shows the designed and optimized parts of electromotor.

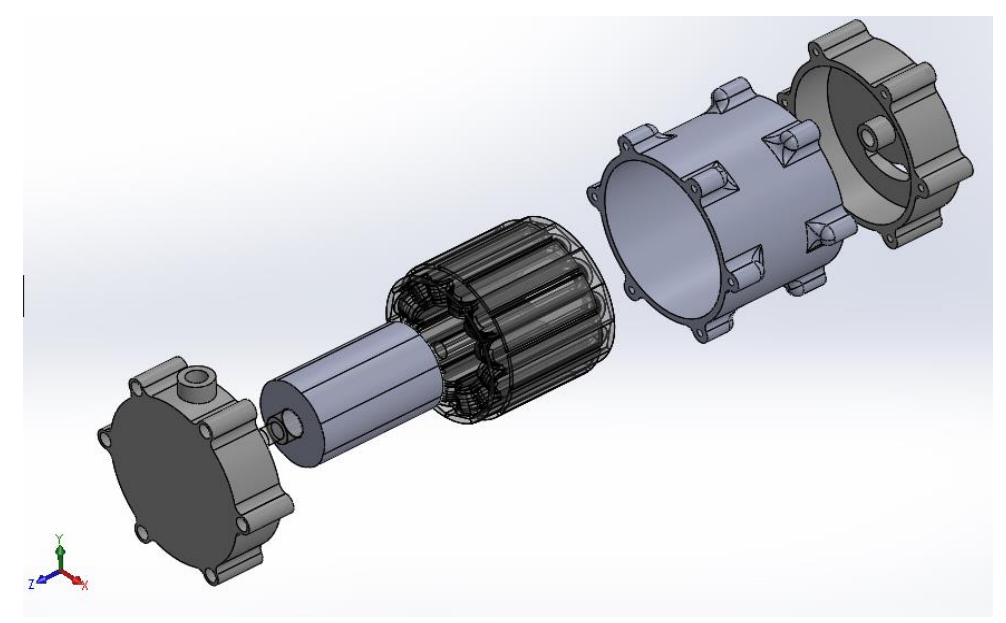

Fig. 2. Pumping aggregate- Electromotor Assembly

\subsection{Flow simulation}

The next step of the project was to analyse the fluid flow. The main purpose of this simulation study was to give a clarification about:

- Total pressure drop at the outlet,

- Cooling performance of the fluid and

- Predicting of disturbances like turbulent flows and cavities. 
Flow Simulation is an extension workbench of SolidWorks and allows performing a wide range of fluid flow analyses. This tool solves the Navier-Stokes flow equations [2] with a discrete numerical technique based on the finite volume method. According to [4], the numerical solution technique employed in Flow Simulation is very robust. Important is the fact, that this tool does not require any user special knowledge about the computational mesh and the numerical methods employed. After setting the known parameters like inlet pressure and outlet flow rate, wall roughness, rotation region about rotor, initial temperature etc. from table 1 in SolidWorks, the simulation is afterward just matter of some mouse clicks. The Figure $3 \mathrm{a}$ shows the results about the total pressure of inlet/outlet. This means the pressure drop defined as a difference between total pressure Inlet und Outlet is very small. Therefore the first question is answered. The Figure $3 \mathrm{~b}$ shows the distributions of pressure with contours and isolines. The Figure $3 \mathrm{c}$ shows the vectors of flow trajectories velocity within Pumping aggregate, which are very important for predicting flow pattern of fluid [3]. The highest rate of velocity was achieved at inlet and remains at the critical Reynolds number. The Figure $3 \mathrm{~d}$ shows the distribution of the temperatures within Pumping aggregate. The highest temperatures was achivied as expected at the gap between Rotor and Stator.

a

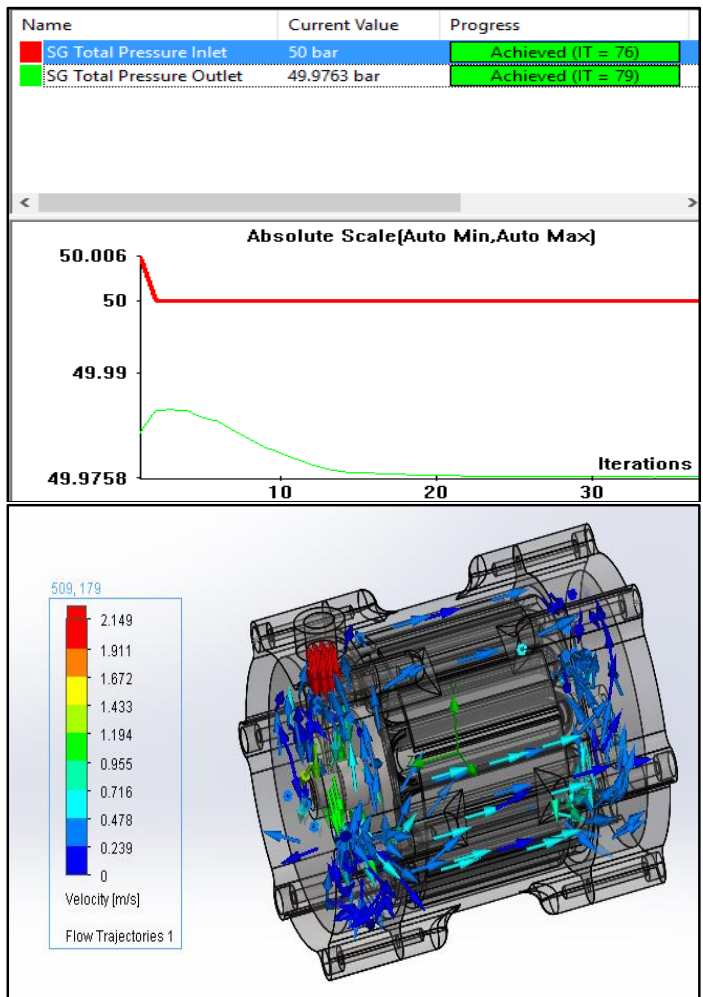

b

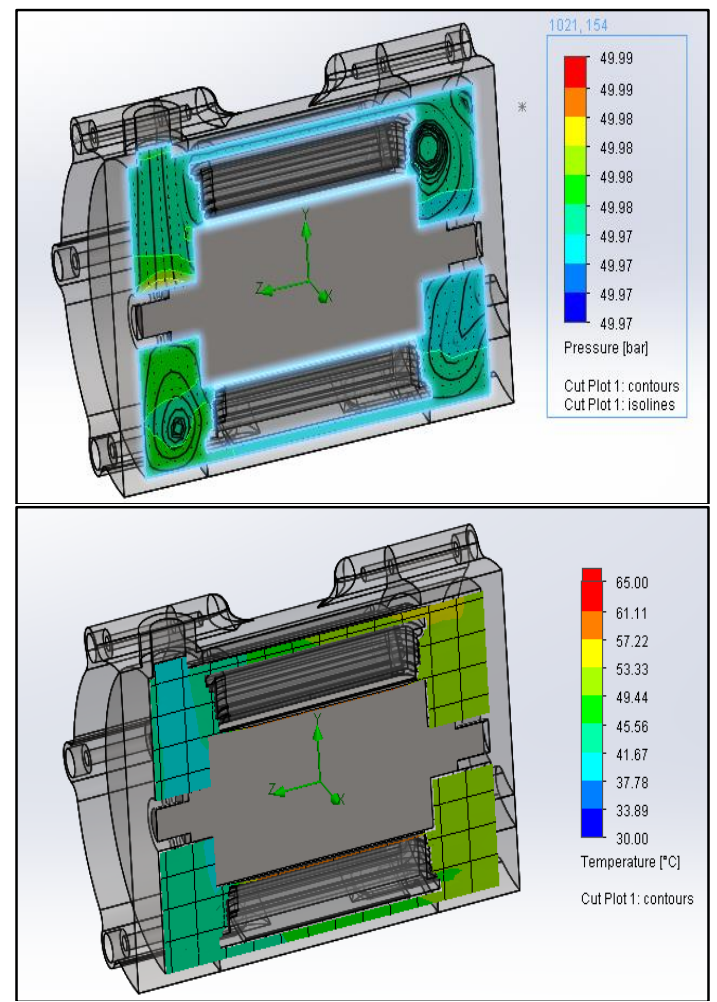

Fig. 3. (a) Pressure drop; (b) pressure; (c) velocity flow trajectories; (d) temperature distribution

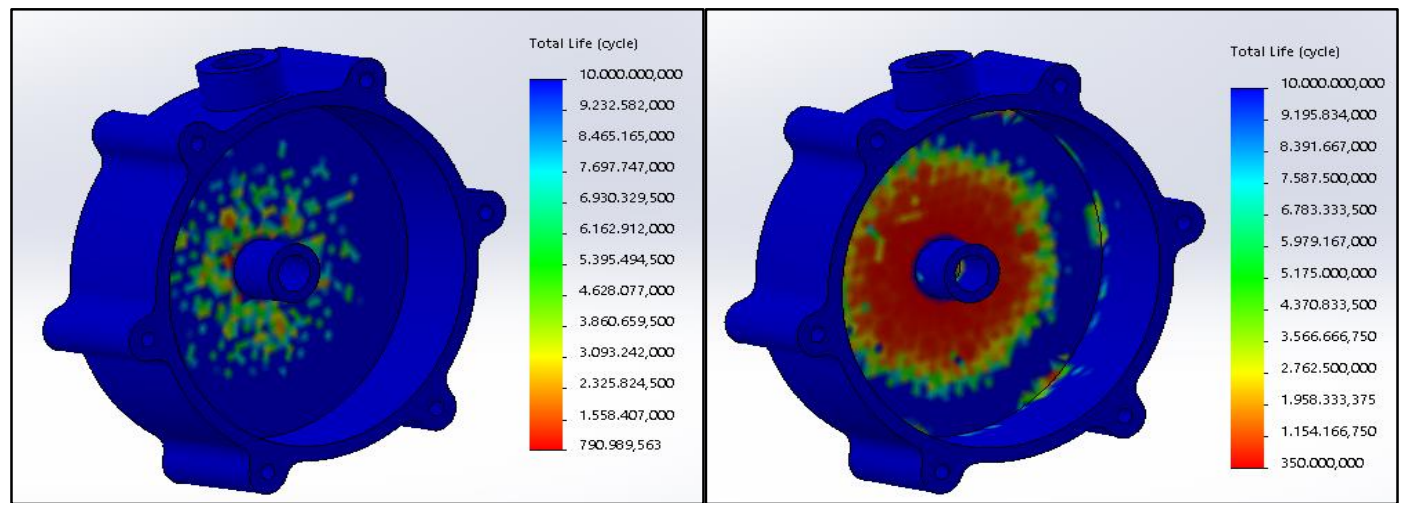

Fig. 4. Inlet Cover total life (a) about 350.000 before optimization and (b) about more than 500.000 Cycles after optimization

\subsection{Fatigue analysis of inlet cover}

Fatigue is the weakening or structural failure of a material caused by frequently applied loads. CAD-embedded SolidWorks Simulation is useful to predict component fatigue failures during the design phase. SolidWorks Simulation 
enables designers to take two approaches to design analysis: design for strength or design for Life. To be more accurate the results from predesigned phase (design for strength) will be used to optimize the part for life [5]. In this project the most strained part of the pumping aggregate and must to be optimized for total life. In the Fig. 4a is represented the predesigned part for total 350.000 Cycles, which is smaller than customer requirement. After increasing the wall thickness from $8 \mathrm{~mm}$ up to $10 \mathrm{~mm}$ the duty cycle of the cover exceeded the customer requirement. The Figure $4 \mathrm{a}$ und $4 \mathrm{~b}$ shows in red the most strained region of the inlet Cover.

\section{Conclusion}

The aim of this work was to show another approach of the solving industrial tasks. During this project was shown, that using of modern engineering software it is possible for very short of time to give plausible solutions for the complex engineering problems. "Plausible solutions" means that results from virtual flow simulation study will not match up to $100 \%$ to real experiments, but they are enough acceptable to reduce the number of real experiments and to keep the engineering costs down. It is known that the refining the mesh parameters of model during the simulations benefits accurate results by enormous calculating time. In the past the processing time was a massive disadvantage. Today thanks to parallel computing feature of modern software allows significantly reducing the calculating time. Furthermore it was possible during the simulation phase to build and evaluate different constructions scenarios of model design, in a bit of time. As mentioned before the mandatory validation was done and has shown only 10-12\% deviation from output parameters of the simulation results So that these results have confirmed the usage of computational fluid dynamic - software for solving of this kind of tasks in present and for researches of pumping aggregates in the future.

\section{References}

[1] J. Dominy; D. N. Bulman, An Active Suspension for a Formula One Grand Prix Racing Car, Journal of Dynamic Systems, Measurement, and Control - Band 107, California (1985) pp.79.

[2] H. Sigloch, Technische Fluidmechanik, Springer, ISBN 978-3-642-22844-5, Dordrecht, Heidelberg, London, New York (2012) pp. 252-260.

[3] Dassault Systemes - SolidWorks Corporation, User Guide Tutorial of SolidWorks Flow Simulation, Euronext Paris: \#13065, DSY.PA Vélizy-Villacoublay, France (2014) pp. 51-59.

[4] R. Singh, M. Nataraj, Design and Analysis of pump impeller using SWFS, World Journal of Modelling and Simulation, Vol. 10: No.2, ISSN 1 746-7233, England, UK, (2014), pp. 152-160.

[5] K, Chang, Product Evaluation using CAD/CAE, Project S3: Structural FEA and Fatigue Analysis Using SolidWorks Simulation, Elsevier, ISBN 9780123984692, Amsterdam (2013), pp. 525-530. 